\title{
ESTRATEGIAS DE COMUNICACIÓN EN LAS ADMINISTRACIONES PÚBLICAS A TRAVÉS DE LA PUBLICIDAD IMPRESA
}

\author{
Jesús Bermejo-Berros
}

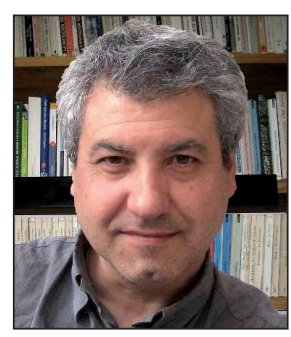

Jesús Bermejo-Berros, profesor titular de comunicación audiovisual y publicidad de la Universidad de Valladolid, es doctor en psicología cognitiva y DEA en psicología por la Universidad de París VIII. Ha sido profesor en las universidades de París VIII, Autónoma de Madrid, Salamanca, Complutense y Toulouse-le-Mirail. Es director de LipsiMedia (Laboratorio de Investigación de Publicidad y Psicología de los Media) de la Universidad de Valladolid y codirector de la revista Pensar la publicidad. Autor de varios libros, como Publicidad y cambio social. Contribuciones históricas y perspectivas de futuro; Narrativa audiovisual. Investigación y aplicaciones; Hombre y pensamiento. El giro narrativo en ciencias sociales y humanas; o Caleidoscopio cinematográfico.

Universidad de Valladolid Facultad de Ciencias Sociales, Jurídicas y de la Comunicación Po Ezequiel González, 32 (Mahonías). 40002 Segovia jbermejo@hmca.uva.es

\section{Resumen}

Se presentan los resultados de una investigación sobre las estrategias informativo-persuasivas de la publicidad gráfica española comercial e institucional. Para ello se seleccionaron todas las publicaciones que un consumidor podía adquirir en un período preciso que se repite cíclicamente. El análisis de cada uno de los 7.704 anuncios insertos en el conjunto de las 232 publicaciones del corpus ha permitido mostrar que existen diferencias entre las estrategias utilizadas en la publicidad comercial y las que utilizan las administraciones públicas en su comunicación con los ciudadanos.

\section{Palabras clave}

Estrategias persuasivas, Publicidad gráfica, Publicidad comercial, Publicidad institucional, Administraciones públicas.

\section{Title: Communication strategies in public administration through print advertising}

\begin{abstract}
We present the results of research that has revealed informative-persuasive strategies of current Spanish commercial and institutional display advertising. The study selected 232 periodicals for analysis, which included 7,704 advertisements. Differences were identified between the strategies used in commercial advertising and those used in government communications with citizens.
\end{abstract}

\section{Keywords}

Persuasion, Advertising, Display advertising, Institutional advertising.

Bermejo-Berros, Jesús. "Estrategias de comunicación en las administraciones públicas a través de la publicidad impresa". El profesional de la información, 2011, julio-agosto, v. 20, n. 4, pp. 399-405.

http://dx.doi.org/10.3145/epi.2011.jul.06

\section{Introducción}

La inversión en comunicación publicitaria en España en el siglo XX se ha destinado en su mayor parte a fines comerciales. Con la llegada de la democracia, las administraciones e instituciones desarrollaron junto a acciones comerciales como loterías y promoción turística, inversiones publicitarias en asuntos de interés público, en sentido amplio. Esta inversión sigue siendo en la actualidad proporcionalmente pequeña comparada con la desarrollada por las empresas privadas, pues no supera un 5,5\% del total de la inversión publicitaria en España, aunque en términos de presupuesto y difusión ya comienza a ser significativa (Infoadex, 2011).

El 40,3\% de la inversión de las administraciones públicas en 2010, unos 72 millones de euros, corresponde a publicidad impresa, que incluye prensa, revistas y dominicales (Medio público, 2011). Además se debe subrayar que la comunicación de las administraciones cumple funciones sociales y de 
integración democrática que le confieren un papel dinamizador del sistema político y social.

Aun cuando existen numerosas evidencias de la existencia de protopublicidad institucional en la antigüedad, desde finales del siglo XIX y principios del XX, período en el que los especialistas de historia de la publicidad emplazan la aparición de la publicidad moderna, observamos que las administraciones públicas han ido utilizando el mismo tipo de canales de comunicación que la publicidad comercial (Eguizábal, 1998; Checa, 2007). Dada la hegemonía de esta última, una cuestión que se plantea es saber si la Administración está utilizando en sus mensajes el mismo tipo de estrategias de comunicación que las empresas comerciales o si, por el contrario, tiene algún tipo de especificidad. El objetivo del presente trabajo es indagar esta cuestión.

\section{La comunicación de las administraciones dentro del sistema publicitario}

Como ha analizado en profundidad Antonio Caro, la definición contemporánea de publicidad abarca al menos siete dimensiones interrelacionadas entre sí que cubren desde su funcionalidad como vehículo para elevar a la escena pública mensajes interesados, su carácter instrumental para mediar entre la producción y el consumo así como para activar la demanda desde la oferta, hasta su contribución a la creación de la imagen de marca o de imágenes institucionales (Caro, 2007). Todas esas dimensiones hacen de la publicidad un sistema en el que no hay mensajes aislados sino todo un entramado comunicacional amplio y dinámico.

La publicidad forma parte de un sistema económico y al mismo tiempo ha adquirido en las últimas décadas tanta relevancia, dada su omnipresencia en la comunicación social, que también forma un sistema cultural que influye en el sistema cognitivo-afectivo de la persona. El procesamiento que hacen los ciudadanos de la información de las administraciones públicas se hace dentro de ese entramado comunicacional donde la publicidad comercial es hegemónica. Por tanto, para entender aquella es necesario situarla en relación a ésta.

Uno de los subsistemas publicitarios más importantes sigue siendo el gráfico, presente no sólo en soportes bidimensionales clásicos como el papel (prensa, revistas, dominicales), sino también en soportes digitales. Según Infoadex la inversión en publicidad gráfica en España en 2010 representa el $34,2 \%$ del total de inversión en medios convencionales, unos 1.904 millones de euros. Dentro de ésta, la publicidad impresa es también uno de las más utilizadas por las administraciones públicas: de los 180 millones de euros invertidos por éstas en 2010, 72 corresponden a este tipo de publicidad (Medio público, 2011).

A partir de estos datos se plantea la cuestión de conocer qué proponen las administraciones públicas a los ciudadanos a través de estas comunicaciones y qué estrategias utilizan para influir en ellos. Analizar publicidades aisladas es un procedimiento aleatorio que carece de fiabilidad y validez. Seleccionar una muestra de unos cuantos anuncios no permite extrapolaciones sobre el universo publicitario analizado, lo que impide extraer conclusiones que respondan a la anterior interrogante, con grados de fiabilidad y validez suficientes. Por ello es necesario estudiar subsistemas en su conjunto. Esto se confronta de inmediato con la dificultad de la tarea pues el corpus de análisis es muy grande y de ahí la escasez de estudios de este tipo.

Por otro lado tenemos que hacer algunas distinciones sobre los diferentes tipos de publicidad gráfica. Partiremos de una primera gran dicotomía entre publicidad comercial e institucional. Aunque los límites entre ambas no estén del todo definidos, y aun cuando ambas son empleadas tanto por las empresas como por las instituciones públicas, puede decirse que globalmente, mientras la publicidad comercial persigue la promoción de productos y servicios con fines lucrativos, la institucional trata de convencer para actuar en favor de alguna idea, sin buscar el beneficio económico directo y, cuando es de las administraciones públicas, tiene como fin último el interés general (Martínez; Vizcaíno, 2008, p. 4).

A partir de los diferentes tipologías propuestas (Sotelo, 2001; Martínez, 2009; Cortés, 2011), podemos distinguir cuatro tipos de publicidad institucional gráfica:

- Empresarial. La empresa busca dar una buena imagen de sí misma mostrando su compromiso con alguna causa, generalmente ajena a su actividad empresarial (por ejemplo, una campaña de Movistar favoreciendo la educación de los niños del tercer mundo).

- Agencias internacionales no gubernamentales. Su interés es concienciar sobre cuestiones que consideran importantes para el conjunto social (por ejemplo, Amnistía internacional).

- Empresas comerciales en asociación con agencias internacionales. Cada vez es más frecuente que lo comercial se mezcle con lo institucional entendiendo que el beneficio es mutuo bajo la fórmula del patrocinio (por ejemplo, las campañas mundiales de alimentos de Benetton y WFP).

- Administraciones públicas. Desde 2005 existe una reglamentación que determina no sólo lo que deben sino sobre todo lo que no deben informar las administraciones públicas (Ley 29/2005 sobre publicidad y comunicación institucional y Ley 30/2007).

A su vez, dentro de la anterior y de acuerdo con Cortés (2011), las administraciones públicas (estatales, autonómicas o locales) hacen cuatro tipos de publicidad:

- Institucional informativa, que se limita a: informar sobre trámites y plazos con la administración y aportar directrices a los ciudadanos sobre cómo actuar; informar sobre la existencia, la composición y funcionamiento de las instituciones públicas; e informar a los ciudadanos sobre sus derechos y obligaciones legales (por ejemplo Hacienda somos todos); difundir las actividades, los proyectos ejecutados, los resultados obtenidos, en relación con los servicios prestados por cada administración pública.

- Institucional comercial, que es aquella que bajo una lógica mercantilista, busca clientes y mercados para el país, comunidad autónoma o municipio que es gobernado por una administración concreta. Ejemplos de este tipo de campañas serían las de loterías, ferias, eventos, turismo y promoción nacional, regional o local. 
- Electoral, que se lleva a cabo en las campañas electorales, cumpliendo unos espacios y unos tiempos determinados, repartidos por la Junta Electoral.

- Con fines sociales, que busca la sensibilización de los ciudadanos, fomentando conductas o hábitos para la convivencia, el bienestar social, la salud pública (tabaquismo, sida, maltrato, etc.).

\section{Las estrategias persuasivas en el conjunto de la publicidad impresa}

El objetivo de la presente investigación es identificar las estrategias argumentativas de las administraciones públicas en la publicidad impresa en comparación con las de la publicidad comercial. Para ello se seleccionaron todas las publicaciones susceptibles de ser adquiridas en el mercado español, bien directamente en un quiosco de venta de prensa, bien a través de envío por correo postal. El período seleccionado fue el mes de octubre de 2010 (primera semana para los diarios y semanarios, primera quincena y mes de octubre para las publicaciones mensuales, bimestrales y semestrales). Se cubre por tanto un período de estimulación cíclica del lector en un bucle iterativo a lo largo del año en el que encontramos varios ciclos de este tipo.

El corpus está formado por un total de 232 publicaciones, que incluye todas las posibles en cualquier sector y tipo de publicación, tanto de carácter generalista como especializado, que insertaran publicidad, y que podían encontrarse en un quiosco de prensa físico en la calle o en la red. El corpus agrupa un total de 23 categorías de publicación que incluyen todo el espectro de productos que el consumidor puede adquirir en el mercado y para el que se hace publicidad impresa (tabla 1). Tenemos así los diarios nacionales de mayor tirada (El país, El mundo, etc.) y también diarios regionales y locales; todo tipo de revistas, desde actualidad como Tiempo o Época; de sociedad como Cosmopolitan o Lecturas; de historia como El siglo de Europa; de juventud como Superpop; economía como Capital, etc.).

Cada uno de los 7.704 anuncios insertos en las citadas 232 publicaciones ha sido analizado en función de las estrategias argumentativas utilizadas, considerando que argumentar es buscar a través del discurso la manera de llevar a un auditorio dado a una cierta acción (Grize, 1981, p. 30). En la comunicación publicitaria gráfica se utilizan diferentes tipos de códigos (icónicos, verbales, tamaños, color, iluminación, etc.) para construir los mensajes persuasivos. Mediante la articulación de estos códigos en un mensaje unificado se busca influir, transformar o reforzar la legitimación de creencias y comportamientos (Plantan, 1996, p. 24).

La historia de la persuasión, que se puede remontar a la Retórica de Aristóteles, ha mostrado que la argumentación puede adoptar diferentes estrategias dependiendo de los destinatarios y fines perseguidos (Oléron, 1983; BermejoBerros, 2004; León, 2009). Sin embargo hasta ahora no existe un estudio que haya indagado la presencia de estrategias argumentativas en la publicidad española de manera sistemática abarcando un ciclo amplio completo.

Partiendo de las distinciones operadas en la historia de la persuasión, que han permitido identificar diferentes tipos de estrategias argumentativas (Perloff, 2003; Briñol et al. 2001; Bermejo-Berros, 2004; León, 2009), hemos procedido a su aplicación al corpus de la publicidad impresa española del presente estudio, obteniendo como resultado la aparición de un total de 14 tipos de estrategias argumentativas. Es decir, existen en la publicidad impresa española 14 maneras diferentes de intentar persuadir al lector:

$1 F$, credibilidad por experiencia y competencia de la fuente

$2 \mathrm{~F}$, credibilidad por imparcialidad de la fuente

$3 \mathrm{~F}$, atractivo por prestigio de la fuente

$4 \mathrm{~F}$, atractivo por similitud con la fuente

$5 \mathrm{~F}$, atractivo físico de la fuente

$6 \mathrm{~F}$, poder

$1 \mathrm{M}$, logos

$2 \mathrm{M}$, pathos

$3 \mathrm{M}$, ethos

$4 \mathrm{M}$, apelaciones emocionales fuertes

$5 \mathrm{M}$, inoculación

$6 \mathrm{M}$, apoyo

7M, humor

$8 \mathrm{M}$, participativas y de contacto.

Aunque la mayoría de los anuncios del corpus utiliza una única estrategia argumentativa, adecuándose así al principio de la proposición única de venta (unique selling proposition, USP, Reeves, 1961), un 18,4\% de los anuncios utiliza estrategias mixtas (dos estrategias y muy excepcionalmente tres). A efectos del análisis se ha tomado en consideración el total de estrategias utilizadas en el total de los anuncios de la investigación.

Las estrategias argumentativas racionales dominan sobre las emocionales

Sólo presentaremos aquí (apartados 3.1 y 3.2) dos resultados que vienen a contradecir dos ideas que circulan entre algunos analistas de la publicidad gráfica:

\subsection{Publicidad racional versus publicidad emocional}

Hoy se viene afirmando por parte de algunos autores que la publicidad es más emocional que racional (Scott et al., 2001; Gobé, 2005; Espantaleón, 2006; López, 2007). El siguiente análisis vendría a mostrar que esta afirmación no se puede hacer extensiva a toda la publicidad, como indican los resultados de la presente investigación.

Como muestra el gráfico 1, las tres estrategias más utilizadas en el conjunto de publicaciones son la 1M (logos), presente en el $22,8 \%$ del total de anuncios del corpus. En segundo lugar la $1 \mathrm{~F}$ (credibilidad por experiencia y competencia de la fuente), utilizada en el $12,7 \%$ y, en tercer lugar, la 2M ( $p a-$ thos), a la que se recurre en el $10,9 \%$.

El logos es la razón, el reclamo publicitario, la oferta, el descuento, el precio. El logos también propone un producto que presenta una ventaja con respecto a los competidores (Joannis, 1995, p. 128). Por ejemplo, utilizando la demostración puede mostrarse una ventaja ligada al rendimiento del producto (una pila que dura más) o a su explotación (un 


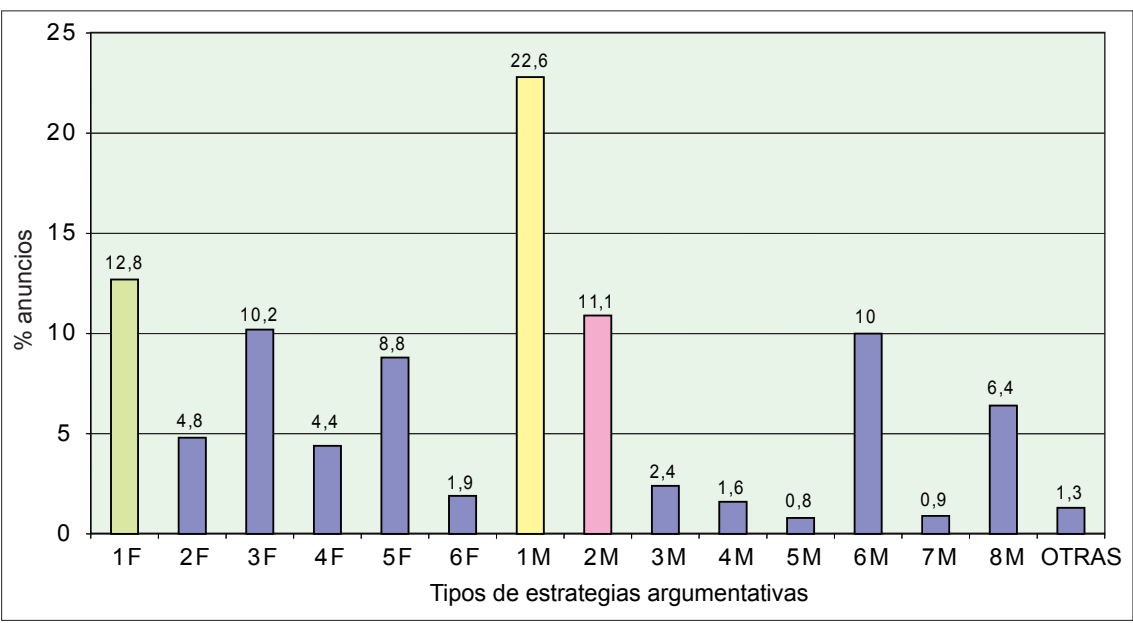

Gráfico 1. Estrategias argumentativas de la publicidad impresa

aire acondicionado más silencioso, una aspiradora se guarda más fácilmente).

La segunda estrategia más utilizada es la $1 \mathrm{~F}$ (credibilidad por experiencia y competencia de la fuente), en la que el anuncio utiliza una fuente que canaliza el mensaje persuasivo apoyándose en su experiencia y competencia.

La tercera más empleada es la $2 \mathrm{M}$ (pathos). Si las dos anteriores estrategias están ligadas a la razón, el pathos apela a las emociones y sentimientos: pone el acento sobre la deseabilidad de las consecuencias que se desprenderían de la aceptación de la posición evocada. Nos traslada así a atmósferas placenteras, mundos imaginarios, de ensoñación, de aventura y sensaciones agradables. Si el pathos aparece en tercer lugar (10,9\% del total de anuncios del corpus), y tiene que ver con emociones y sentimientos, la 6M (apoyo) que le sigue muy de cerca en porcentaje (10\%), también se corresponde con la razón y por tanto equilibra la presencia de la apelación emocional que representa el pathos. Por tanto en conjunto aparecen unas estrategias variadas en las que la publicidad emocional no domina; bien al contrario, es la razón la más utilizada.

\subsection{Apelación al erotismo, la sensualidad y el atrac- tivo físico}

Un segundo resultado viene a contradecir la idea bastante extendida de que la publicidad utiliza mucho la apelación al atractivo físico (Cáceres; Soloaga, 2008; Díaz, 2007; García, 2007; Parro; Pérez, 2000; Pérez-Gauli, 2000). Incluso se ha afirmado que la abundancia de erotismo en publicidad contribuye a la "sexualización de la cultura" (Soley, 2008, p. 94). Los datos de la presente investigación indican que esta estrategia existe efectivamente ( $8,8 \%$ del total de anuncios), pero no es en conjunto la mayoritaria.

Hay un doble fenómeno en relación a esta estrategia de atractivo físico. Por un lado existe una concentración de su presencia en determinadas publicaciones específicas. En los datos de la tabla 1 aparecen en amarillo las estrategias más utilizadas en cada categoría de publicación. La estrategia 5F sólo es la de mayor frecuencia en Moda. Además en verde en la tabla 1 se muestran las estrategias más utilizadas en segundo lugar. Aquí también aparece sólo en la categoría Sociedad.
Por otro lado hay que tener en cuenta que todas las publicaciones no tienen la misma presencia en nuestra sociedad. Así por ejemplo, en el corpus hay categorías con escaso número de publicaciones (por ejemplo, una sola revista de humor o de bricolage) mientras que otras son muy abundantes (por ejemplo, 11 revistas de Moda y 21 de Sociedad). Además estas últimas suelen tener un alto número de páginas y de anuncios. Esto hace que el peso de estas dos categorías en el conjunto sea mayor (que además se vería aumentado, en cuanto a sus efectos de cultivo, por la toma en cuenta de las tiradas de venta de cada ejemplar de revista). Por tanto y dado que la estrategia $5 F$ está muy presente en las publicaciones de Moda y Sociedad, el peso de éstas sobre el total del $8,8 \%$ (correspondiente al conjunto de todas las categorías de publicación) está en realidad concentrado esencialmente en estas dos categorías. Esto provoca una exposición diferencial de los lectores. Por ejemplo, una persona que lea regularmente revistas de moda o sociedad tendrá una mayor exposición a este tipo de anuncios erotizantes que quienes lean otras revistas especializadas (de historia, cine, bricolage, etc.).

\section{Estrategias persuasivas en la publicidad impresa de las administraciones públicas}

La publicidad de las administraciones públicas ha sido ubicada en este análisis junto a los otros tres tipos de publicidad institucional pues ello permite establecer puntos de comparación. Como muestra la tabla 2, de los 7.704 anuncios que conforman el corpus, sólo 412 incluyen algún tipo de anuncio institucional. El 3,8\% del total son anuncios de las administraciones públicas, llegando al 5,4\% si incluimos también el resto de publicidad institucional. La distribución entre las publicaciones de este $5,4 \%$ es muy desigual, concentrándose sobre todo en los diarios (una media de 11,2\%). Hay numerosas categorías de publicación que no insertan publicidad institucional (como moda, humor, erotismo, música, cine, etc.). Algunas categorías muy delimitadas concentran un determinado tipo de publicidad, como es el caso de viajes que incluye publicidad institucional comercial de promoción turística de alguna comunidad autónoma.

Hay categorías de publicación que no insertan publicidad institucional, como moda, humor, erotismo, música, cine, etc.

Los cuatro tipos de publicidad institucional utilizan un número restringido de estrategias (tabla 2). Cada uno de estos tipos concentra su publicidad sobre determinadas estrategias específicas. Así, las campañas institucionales de empresas utilizan sobre todo la estrategia $3 \mathrm{M}\left(\right.$ ethos $\left.^{2}\right)$. Por su parte en las campañas de las ONGs predomina la estrategia 


\begin{tabular}{|c|c|c|c|c|c|c|c|c|c|c|c|c|c|c|c|}
\hline \multirow{2}{*}{ Categorías de publicación } & \multicolumn{15}{|c|}{ Estrategias argumentativas } \\
\hline & otras & $1 F$ & $2 \mathrm{~F}$ & $3 F$ & $4 F$ & $5 F$ & $6 \mathrm{~F}$ & $1 \mathrm{M}$ & $2 \mathrm{M}$ & $3 M$ & $4 \mathrm{M}$ & $5 \mathrm{M}$ & $6 \mathrm{M}$ & $7 \mathrm{M}$ & $8 \mathrm{M}$ \\
\hline Arte y diseño & & 72 & 0 & 5 & 6 & 39 & 1 & 72 & 42 & 6 & 1 & 1 & 16 & 0 & 7 \\
\hline Juventud & & 21 & 3 & 19 & 5 & 5 & 0 & 21 & 9 & 0 & 1 & 0 & 0 & 0 & 4 \\
\hline Hogar y confección & 66 & 41 & 9 & 2 & 14 & 19 & 7 & 124 & 101 & 22 & 1 & 1 & 43 & 3 & 29 \\
\hline Automoción & & 75 & 69 & 56 & 10 & 16 & 11 & 261 & 31 & 8 & 4 & 4 & 67 & 0 & 43 \\
\hline Televisión & & 5 & 4 & 4 & 1 & 1 & 4 & 4 & 14 & 6 & 0 & 2 & 8 & 0 & 38 \\
\hline Vinos & & 35 & 4 & 7 & 0 & 0 & 2 & 31 & 19 & 23 & 5 & 7 & 33 & 2 & 17 \\
\hline Música & & 39 & 4 & 29 & 47 & 17 & 3 & 9 & 57 & 4 & 0 & 3 & 4 & 4 & 12 \\
\hline Salud/Cuidado personal & & 87 & 43 & 24 & 30 & 59 & 7 & 148 & 71 & 12 & 13 & 13 & 130 & 9 & 38 \\
\hline Historia & & 26 & 4 & 13 & 14 & 4 & 3 & 14 & 33 & 0 & 1 & 1 & 13 & 1 & 4 \\
\hline Sociedad & & 72 & 0 & 157 & 44 & 119 & 22 & 85 & 59 & 16 & 13 & 4 & 49 & 13 & 39 \\
\hline Erotismo & & 23 & 0 & 0 & 0 & 0 & 0 & 0 & 2 & 0 & 5 & 0 & 5 & 2 & 1 \\
\hline Humor & & & 0 & 0 & 1 & 1 & 0 & 2 & 0 & 0 & 0 & 0 & 0 & 0 & 0 \\
\hline Formación & & 11 & 0 & 7 & 2 & 6 & 0 & 20 & 6 & 5 & 1 & 0 & 6 & 1 & 6 \\
\hline Campo & & 2 & 0 & 8 & 6 & 0 & 0 & 0 & 1 & 0 & 0 & 0 & 8 & 0 & 0 \\
\hline Divulgación científica & & 12 & 6 & 11 & 5 & 7 & 3 & 35 & 2 & 5 & 1 & 1 & 15 & 1 & 14 \\
\hline Moda & & 104 & 44 & 212 & 45 & 243 & 9 & 100 & 84 & 15 & 11 & 2 & 56 & 7 & 20 \\
\hline Animales & & 22 & 6 & 5 & 0 & 6 & 0 & 126 & 60 & 5 & 2 & 0 & 18 & 0 & 4 \\
\hline Viajes & 4 & 6 & 0 & 9 & 3 & 0 & 1 & 10 & 8 & 3 & 2 & 0 & 41 & 0 & 15 \\
\hline Suplem. moda en diarios & & 5 & 2 & 15 & 2 & 12 & 0 & 7 & 6 & 1 & 0 & 0 & 5 & 1 & 1 \\
\hline Actualidad & & 2 & 3 & 4 & 0 & 0 & 1 & 10 & 9 & 2 & 1 & 1 & 10 & 1 & 4 \\
\hline Economía & & 2 & 3 & 0 & 1 & 0 & 2 & 35 & 4 & 3 & 0 & 0 & 3 & 1 & 1 \\
\hline Cine & & 11 & 32 & 10 & 6 & 6 & 1 & 8 & 10 & 1 & 15 & 1 & 1 & 1 & 3 \\
\hline Bricolage & & & 0 & 3 & 0 & 0 & 0 & 8 & 0 & 0 & 0 & 0 & 2 & 0 & 2 \\
\hline Diarios deportivos ${ }^{\mathrm{a}}$ & & 27 & 1 & 11 & 1 & 3 & 15 & 39 & 10 & 2 & 1 & 1 & 9 & 2 & 21 \\
\hline Semanarios deportivos ${ }^{b}$ & & 24 & 2 & 3 & 9 & 6 & 3 & 22 & 8 & 1 & 4 & 2 & 11 & 5 & 8 \\
\hline Revistas deportivas $^{c}$ & & 9 & 5 & 24 & 9 & 5 & 4 & 35 & 14 & 1 & 2 & 0 & 2 & 7 & 25 \\
\hline El país & 4 & 34 & 9 & 26 & 7 & 24 & 15 & 93 & 36 & 9 & 6 & 5 & 65 & 3 & 22 \\
\hline El norte de Castilla & & 25 & 24 & 0 & 20 & 0 & 0 & 101 & 0 & 0 & 0 & 0 & 36 & 0 & 25 \\
\hline El adelantado & & 56 & 3 & 33 & 9 & 4 & 4 & 112 & 27 & 6 & 13 & 1 & 22 & 1 & 10 \\
\hline Diario montañés & 23 & 36 & 11 & 22 & 11 & 42 & 3 & 62 & 69 & 16 & 2 & 3 & 18 & 2 & 19 \\
\hline El mundo & & 27 & 3 & 21 & 4 & 3 & 12 & 40 & 11 & 5 & 9 & 3 & 20 & 1 & 34 \\
\hline La razón & & 24 & 9 & 24 & 5 & 11 & 3 & 12 & 10 & 0 & 6 & 0 & 6 & 0 & 14 \\
\hline Total (n) & 97 & 935 & 303 & 764 & 317 & 658 & 136 & 1.646 & 813 & 177 & 120 & 56 & 722 & 68 & 480 \\
\hline Total (\%) & 1,4 & 12,8 & 4,1 & 10,5 & 4,3 & 9,0 & 1,9 & 22,6 & 11,1 & 2,4 & 1,6 & 0,8 & 9,9 & 0,9 & 6,5 \\
\hline
\end{tabular}

Tabla 1. Distribución del número de anuncios según las categorías de publicación y de estrategia argumentativa

a. Publicaciones deportivas diarias como diario As, Marca, Mundo deportivo.

b. Publicaciones deportivas semanales como Don Balón o Gigantes.

c. Publicaciones deportivas mensuales como Basket life, Futbolista, NBA, Ciclismo a fondo o Deportes sólo golf.

\begin{tabular}{|c|c|c|c|c|c|c|c|c|c|c|c|c|c|c|c|}
\hline \multirow{2}{*}{ Tipos de publicidad institucional } & \multicolumn{15}{|c|}{ № de anuncios en cada estrategia argumentativa } \\
\hline & $\mathrm{n}$ & $1 F$ & $2 \mathrm{~F}$ & $3 F$ & $4 \mathrm{~F}$ & $5 \mathrm{~F}$ & $6 \mathrm{~F}$ & $1 \mathrm{M}$ & $2 \mathrm{M}$ & $3 \mathrm{M}$ & $4 \mathrm{M}$ & $5 \mathrm{M}$ & $6 \mathrm{M}$ & $7 \mathrm{M}$ & $8 \mathrm{M}$ \\
\hline Publicidad empresarial & 66 & 4 & & & & & & 5 & & 57 & & & & & \\
\hline ONGs & 43 & & & & & & & & & & 36 & & & & 7 \\
\hline Empresas y agencias no gubernamentales & 12 & & & & & & & & & & 12 & & & & \\
\hline Administraciones públicas & 291 & 14 & & & & & & 131 & 39 & 3 & 98 & 4 & 2 & & \\
\hline Total (n) & 412 & 18 & & & & & & 136 & 39 & 60 & 146 & 4 & 2 & & 7 \\
\hline
\end{tabular}

Tabla 2. Estrategias argumentativas utilizadas en los anuncios institucionales del corpus $(n=412)$ 


\begin{tabular}{|c|c|c|c|c|c|c|c|c|c|c|c|c|c|c|c|}
\hline \multirow{2}{*}{$\begin{array}{l}\text { Tipos de publicidad de las } \\
\text { administraciones públicas }\end{array}$} & \multicolumn{15}{|c|}{ № de anuncios en cada estrategia argumentativa } \\
\hline & $\mathrm{n}$ & $1 F$ & $2 \mathrm{~F}$ & $3 F$ & $4 \mathrm{~F}$ & $5 \mathrm{~F}$ & $6 \mathrm{~F}$ & $1 \mathrm{M}$ & $2 \mathrm{M}$ & $3 \mathrm{M}$ & $4 \mathrm{M}$ & $5 \mathrm{M}$ & $6 \mathrm{M}$ & $7 M$ & $8 \mathrm{M}$ \\
\hline Publicidad con fines sociales & 104 & & & & & & & & & & 98 & 4 & 2 & & \\
\hline Publicidad informativa & 145 & 14 & & & & & & 131 & & & & & & & \\
\hline Publicidad electoral & 0 & & & & & & & & & & & & & & \\
\hline Publicidad comercial & 42 & & & & & & & & 39 & 3 & & & & & \\
\hline Total (n) & 291 & 14 & & & & & & 131 & 39 & 3 & 98 & 4 & 2 & & \\
\hline
\end{tabular}

Tabla 3. Estrategias argumentativas utilizadas por las administraciones públicas en los anuncios del corpus $(n=291)$

4M (apelaciones emocionales fuertes referidas al miedo o la injusticia).

Con respecto a las administraciones públicas, como muestra la tabla 3, la publicidad informativa se concentra en el logos (1M) representando ella sola el $45 \%$ del total de anuncios de las administraciones públicas, mientras que la estrategia $4 \mathrm{M}$ en la publicidad con fines sociales, representa el $33,7 \%$ del total. No hay ningún anuncio de publicidad electoral pues en el momento de la investigación no era un período de elecciones. Sería interesante hacer extensivo este estudio a un período electoral y comprobar el peso de la publicidad electoral con relación al resto de tipos de publicidad y las estrategias utilizadas en su caso. Por último, la publicidad comercial de las administraciones públicas se concentra en la estrategia del pathos (2M) con un $13,4 \%$ del total de anuncios.

La publicidad impresa de las administraciones públicas utiliza de manera equilibrada estrategias racionales y emocionales

\section{Conclusión}

En conjunto la publicidad de las administraciones públicas se concentra en dos tipos de estrategias argumentativas, una racional, el logos, que representa el $45 \%$ del total de este tipo de anuncios, y otras dos emocionales (4M: centradas en campañas de tráfico o aquellas de lucha contra el maltrato o la drogadicción; 2M: centradas en promoción turística). Estas dos estrategias juntas constituyen el $47 \%$ del total. Por tanto, en el marco de esta investigación, la publicidad impresa de las administraciones públicas utiliza de manera equilibrada estrategias tanto racionales como emocionales.

Por otra parte la publicidad impresa de las administraciones públicas, al igual que el resto de publicidad institucional, utiliza un número más restringido de estrategias argumentativas que la publicidad comercial. Una hipótesis que se desprende de este trabajo es si en el futuro la publicidad institucional seguirá un proceso similar al de la comercial, de multiplicación de sus modos de argumentar para alcanzar sus fines persuasivos en su comunicación con los ciudadanos.

\section{Notas}

1. Esta investigación forma parte del proyecto de investigación del Plan nacional CSO2009-12568-C03-02
2. Competen al ethos los argumentos que apelan a la autoridad de un texto, de una ley religiosa o moral, de una institución o bien de una persona investida con un mandato, de un personaje célebre; también competen a esta categoría los argumentos que utilizan el peso del número y de la tradición. Este tipo de estrategia puede incluir también argumentos tipo $1 \mathrm{~F}$ que enfoquen la atención del receptor sobre la fuente (posición social, etc.).

\section{Referencias}

Bermejo-Berros, Jesús. "Los límites de la persuasión: entre la seducción y la propaganda". En: Eguizábal, Raúl (coord.). La comunicación publicitaria. Antecedentes y tendencias en la sociedad de la información y el conocimiento. Sevilla: Comunicación social ediciones y publicaciones, 2004, pp. 43-70. ISBN 8496082164

Cáceres, María-Dolores; Díaz-Soloaga, Paloma. "El uso del cuerpo en la publicidad de marcas de moda de lujo". En: Investigar la comunicación. Congreso internacional fundacional Asociación Española de Investigación de la Comunicación (AE-IC), Santiago de Compostela, 1 febrero 2008. ISBN 9788461238163

Caro-Almela, Antonio. "Fundamentos epistemológicos y metodológicos para un estudio científico de la publicidad". Pensar la publicidad. Revista internacional de investigaciones publicitarias, 2007, v. 1, n. 1, pp. 55-83.

Checa-Godoy, Antonio. Historia de la publicidad. La Coruña: Netbiblo D.L., 2007. ISBN 978-84-9745-180-2

Cortés-González, Alfonso. "La publicidad institucional en España. Una década en perspectiva". Razón y palabra, 2011, febrero-abril, n. 75.

Díaz-Soloaga, Paloma. "Valores y estereotipos femeninos creados en la publicidad gráfica de las marcas de moda de lujo en España". Anàlisi, Quaderns de comunicació i cultura, 2007, n. 35, pp. 33-67.

Eguizábal-Maza, Raúl. Historia de la publicidad. Madrid: Eresmas \& Celeste, 1998, ISBN 8482111604

Espantaleón, Raquel. "Humanizar las marcas o la moda emocional". Anuncios, 2006, 26 junio, n. 1154.

García-Bandera, Noelia. "Naked or nude? Apuntes sobre publicidad y desnudo en los anuncios de perfumes". Boletín de arte, 2007, n. 28, pp. 507-522.

Gerbner, George; Gross, Larry; Morgan, Michael; Signorielli, Nancy. "Growing up with television: The cultivation perspective". En: Bryant, Jennings; Zillmann, Dolf. (eds). Me- 
dia effects: advances in theory and research. Hillsdale, NJ: Lawrence Elrbaum, 1994, pp. 17-41. ISBN 08058863-5

Gobé, Marc. Branding emocional: el nuevo paradigma para conectar las marcas emocionalmente con las personas. Barcelona: D.L., 2005. ISBN 8493393150

Grize, Jean-Blaise. "L'argumentation : explication ou séduction". En: Linguistique et sémiologie: l'argumentation, Lyon: Presses Universitaires de Lyon, 1981.

Infoadex. Estudios, 2011

http://www.infoadex.es/estudios

Joannis, Henri. De la stratégie marketing à la création publicitaire. Paris, Dunod, 1995. ISBN 2100022164

León, José-Luis. Persuasión pública. Bilbao: Servicio editorial de la UPV, 2009. ISBN 9788498600612

López-Vázquez, Belén. Publicidad emocional. Estrategias creativas. Madrid: Esic, 2007. ISBN 9788473564885

Martínez-Pastor, Esther. Los mensajes publicitarios analizados desde la comunicación y el derecho. Madrid: Universitas, 2009. ISBN 9788479912659

Martínez-Pastor, Esther; Vizcaíno, Ricardo. "Publicidad institucional comofenómeno integrador ante la inmigración en España: Régimen jurídico". Revista latina de comunicación social, 2008, n. 63.

http://redalyc.uaemex.mx/pdf/819/81906309.pdf
Medio público. Publicidad sector público, 2011. http://mediopublico.com/inversiones-publicitarias-administraciones-públicas/informe-publicidad-sector-público

Oléron, Pierre. L'argumentation. Paris: PUF, 1983. ISBN 2130378811

Parro, Alicia; Pérez, Pilar. "Sexo: la gran tentación de la publicidad". En: Capital sección marketing. Madrid: Editorial Gyj., 2000, pp. 82-90.

Pérez-Gauli, Juan-Carlos. El cuerpo en venta. Relación entre arte y publicidad. Madrid: Cátedra, 2000. ISBN 8437618118

Perloff, Richard M. The dynamics of persuasion: communication and attitudes in the $21^{\text {st }}$ century. Mahwah, NJ, Lawrence Erlbaum Associates, 2003. ISBN 0805840885

Plantin, Christian. L'argumentation. Paris: Seuil, 1996. ISBN 2020229560

Reeves, Rosser. Reality in advertising. New York: Alfred A. Knopf, 1961. ISBN 0394442288

Scott, Robinette; Brand, Claire; Lenz, Vicki. Marketing emocional. Barcelona: Gestión, 2001. ISBN 8480886544

Soley-Beltrán, Patricia. "Erotismo, cuerpo y consumo". En: Rey, Juan (ed.). Publicidad y sociedad. Un viaje de ida y vuelta. Zamora: Comunicación social ediciones y publicaciones, 2008.

Sotelo-Enríquez, Carlos. Introducción a la comunicación institucional. Barcelona: Ariel, 2001. ISBN 9788434412835

\section{¡NOVEDAD! ENRIQUECIMIENTO ESPAÑOL PARA SU CATÁLOGO}

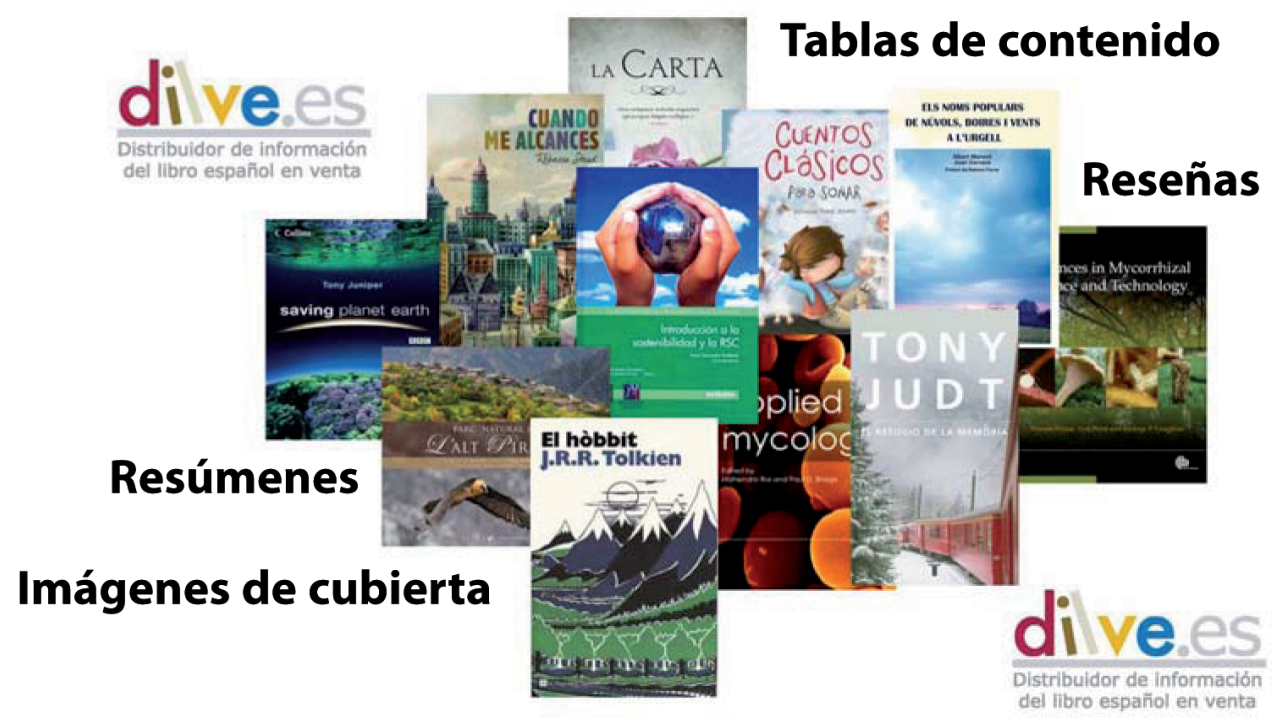

Syndetic Solutions, en colaboración con DILVE, ahora ofrece a su biblioteca imágenes de cubierta, resúmenes, reseñas y tablas de contenido de libros españoles para enriquecer su catálogo en línea.

Por favor contacte con nosotros para recibir prueba gratuita, presupuesto y/o informe de coincidencia entre su colección actual y nuestra base de datos de enriquecimientos. 